\title{
The immunophenotype of epithelial to mesenchymal transition inducing transcription factors in salivary gland adenoid cystic carcinomas
}

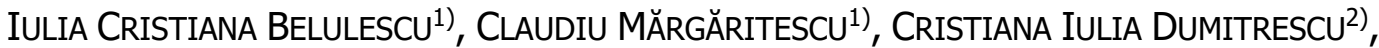 \\ MARIA CRISTina MUNTEANU ${ }^{3)}$, LUMINITA DĂGUCI ${ }^{4}$, OTILIA ClaRA MăRgĂRITESCU ${ }^{5}$, \\ MARIUS MATEI ${ }^{6}$
}

\author{
1) Department of Pathology, University of Medicine and Pharmacy of Craiova, Romania \\ 2) Department of Clinical Pharmacology, University of Medicine and Pharmacy of Craiova, Romania \\ ${ }^{3)}$ Department of Oral and Maxillofacial Surgery, Faculty of Dentistry, University of Medicine and Pharmacy \\ of Craiova, Romania \\ 4) Department of Prosthodontics, University of Medicine and Pharmacy of Craiova, Romania \\ 5) Department of Neurosurgery, Faculty of Medicine, University of Medicine and Pharmacy of Craiova, Romania \\ ${ }^{6}$ Department of Histology, Faculty of Medicine, University of Medicine and Pharmacy of Craiova, Romania
}

\begin{abstract}
Adenoid cystic carcinoma (ACC) is the second most common malignant salivary glands neoplasms with a controversial biological behavior. Even though these tumors grow slowly, they have increased potential for recurrence and distant metastasis. In order to elucidate this behavior, our study aimed to investigate the immunoexpression in such tumors of the most important transcriptional factors [Twist, Snail, Slug, and zinc finger E-box binding homeobox 1 (ZEB1)] involved in the epithelial-mesenchymal transition process. The highest level of expression was recorded for Twist, present in all the investigated cases, followed by the Slug and Snail, while no tumor parenchyma reactivity was noticed for the ZEB1 factor. There were tumor reactivity differences regarding topography, histopathological variant, and nerve and lymph node invasion status. Thus, tumors developed from the intraoral minor salivary glands, with solid pattern, perineural invasion, locally aggressive and with lymph node metastasis were the most reactive. Therefore, these transcription factors could be useful as prognostic biomarkers and efficient therapeutic targets in such salivary malignancies.
\end{abstract}

Keywords: adenoid cystic carcinoma, epithelial-mesenchymal transition, immunohistochemistry, transcription factors, salivary gland.

\section{Introduction}

Adenoid cystic carcinoma (ACC) is considered in many records the second most common malignant salivary glands neoplasms and the first one in the minor salivary glands $[1,2]$. The biological behavior of this tumor is controversial because even though they grow slowly and indolent, the recurrence rate can achieve $74 \%[3,4]$ and, moreover, the distant metastasis seems to be more common than regional recurrences [5]. Thus, if the five-year overall survival rate in patients with $\mathrm{ACC}$ without recurrences is around $70 \%$, this rate drops down to $57 \%$ in patients with recurrences [6], and to $46 \%$ in those cases with distant metastasis [7]. According to data recorded between 1973-2008 by the Surveillance, Epidemiology, and End Results (SEER) Program of the National Cancer Institute, about 3208 people were diagnosed with oral cavity and pharynx ACC, with one-third of the patients with regional ACCs of the major salivary glands having the risk of death [8]. Recent studies have shown that the epithelial-mesenchymal transition (EMT) process appears to be partly responsible for such behavior $[9,10]$. One of the key events of EMT process is the loss of E-cadherin expression, which is regulated by several transcription factors, such as Snail, Slug, Twist, and $\delta \mathrm{EF} 1 /$ zinc finger E-box binding homeobox 1 (ZEB1) [11-14]. Some recent research has indicated that such transcription factors are associated with locoregional invasiveness and distant metastasis which make them useful in evaluating the prognosis of patients with salivary ACC (SACC) [15-18].

\section{Aim}

In this regard, our study aimed to establish the immunophenotype of Snail, Slug, Twist, and ZEB1 transcription factors in SACC.

\section{ㅁ Materials and Methods}

After giving informed consent, 32 patients with salivary gland ACC who underwent resection of their tumors at the Department of Oral and Maxillofacial Surgery from Emergency County Hospital, Craiova, Romania, between 2010 and 2019 were enrolled in our study. The clinical and demographic data were collected form the database of the Department of Surgery, where they have been presented, and the histopathological (HP) data and the correspondent paraffin blocks were retrieved from the Archive of the Laboratory of Pathology from the same Hospital. Repre-

This is an open-access article distributed under the terms of a Creative Commons Attribution-NonCommercial-ShareAlike 4.0 International Public License, which permits unrestricted use, adaptation, distribution and reproduction in any medium, non-commercially, provided the new creations are licensed under identical terms as the original work and the original work is properly cited. 
sentative $4-\mu \mathrm{m}$-thick sections of these paraffin blocks were used for immunohistochemical (IHC) analysis. These were dewaxed and rehydrated and then the endogenous peroxidase activity was blocked by incubation with $3 \%$ hydrogen peroxide for 20 minutes. The antigen retrieval was accomplished by $0.01 \mathrm{M}$ citrate buffer solution ( $\mathrm{pH} 6$ ) in a microwave oven $650 \mathrm{~W}$ for 15 minutes. Then, for 30 minutes, at room temperature, the slides were incubated with $2 \%$ bovine serum albumin (BSA). Subsequently, the slides were exposed overnight, at $4^{\circ} \mathrm{C}$, to the primary antibodies against Twist (1:300), Snail (1:100), Slug (1:150) and ZEB1 (1:100) in a humidified chamber (Table 1). Then the signal was detected and amplified according to the producer's protocols for the LSAB2 detection kit (K0675, Dako, Redox, Romania). 3,3'-Diaminobenzidine tetrahydrochloride (DAB, Dako, K3468) was used to detect the IHC targets, and the slides were counterstained with Hematoxylin (Tunic, Bio-Optica, Romania - M06002). Negative controls were performed by replacing the primary antibodies with phosphate-buffered saline (PBS).

Table 1 - The antibodies and immunostaining protocol

\begin{tabular}{|c|c|c|c|c|}
\hline Antibody & $\begin{array}{c}\text { Clone I } \\
\text { Manufacturer, } \\
\text { Catalog No. }\end{array}$ & Dilution & $\begin{array}{l}\text { Antigen } \\
\text { retrieval }\end{array}$ & $\begin{array}{l}\text { External } \\
\text { positive } \\
\text { control }\end{array}$ \\
\hline Twist & $\begin{array}{c}\text { Rabbit } \\
\text { polyclonal / } \\
\text { Abcam, } \\
\text { ab50581 }\end{array}$ & $1: 300$ & $\begin{array}{c}0.1 \mathrm{M} \\
\text { Citrate, } \\
\mathrm{pH} 6\end{array}$ & Colon \\
\hline Snail & $\begin{array}{c}\text { Rabbit } \\
\text { polyclonal / } \\
\text { Novus } \\
\text { Biologicals, } \\
\text { NBP1-80022 }\end{array}$ & $1: 100$ & $\begin{array}{c}0.1 \mathrm{M} \\
\text { Citrate, } \\
\mathrm{pH} 6\end{array}$ & Kidney \\
\hline Slug & $\begin{array}{c}\text { Rabbit } \\
\text { polyclonal / } \\
\text { Abcam, } \\
\text { ab27568 } \\
\end{array}$ & $1: 150$ & $\begin{array}{c}0.1 \mathrm{M} \\
\text { Citrate, } \\
\mathrm{pH} 6\end{array}$ & Placenta \\
\hline ZEB1 & $\begin{array}{c}\text { Mouse } \\
\text { monoclonal - } \\
\text { CL0151 / } \\
\text { Sigma Aldrich, } \\
\text { AMAb90510 }\end{array}$ & $1: 100$ & $\begin{array}{c}0.1 \mathrm{M} \\
\text { Citrate, } \\
\mathrm{pH} 6\end{array}$ & $\begin{array}{c}\text { Prostate } \\
\text { adenocarcinoma }\end{array}$ \\
\hline
\end{tabular}

ZEB1: Zinc finger E-box binding homeobox 1.

IHC results were analyzed by two independent pathologists (BIC and $\mathrm{MC}$ ) and these were evaluated using the immunoreactivity score (IRS) given by Remmele \& Stegner [19]. According to this score, the slides were quantified with values between 1 and 12, considering both cytoplasmic and nuclear reactivity for all investigated markers.

For statistical analysis, we utilized the Statistical Package for the Social Sciences (SPSS) 10 software package. In order to assess the association between different categorical classes in this study, data was organized in contingency tables, and a $\chi^{2}$ (chi-squared) test was utilized. The analysis of variance (ANOVA) test was used for comparisons of more than two groups of continuous data variables, and a Pearson's correlation coefficients were calculated for analysis of correlations between two sets of continuous variables. A $p$-value $<0.05$ was considered the threshold for statistical significance.

\section{口 Results}

In our casuistry, the mean age at diagnosis was 57.5 years (range, 31-91 years), with males being more commonly affected then females (59.37\% versus $40.63 \%)$. In $50 \%$ of cases, ACCs were localized in the major salivary gland, and in half of these cases, developed from the parotid gland $(28.12 \%)$. However, oral minor salivary glands developed ACCs in the other half of the patients with the hard palate mucosa as the most affected (18.75\%). Histopathologically, the most reported variant was the solid type (46.88\%), followed by the tubular variant $(34.37 \%)$ and in the last place was the cribriform variant $(18.75 \%)$. Perineural invasion was found in $71.87 \%$ patients, and lymph nodes metastases was found in $18.75 \%$ patients. Most patients presented in stage II-pTNM (71.87\%), followed by patients with stage III-pTNM (18.75\%), patients with stage IV-pTNM $(6.25 \%)$ and one patient with stage I-pTNM (3.12\%). In $40.62 \%$ of cases were identified positive surgical margins.

\section{Twist expression}

In the normal tissue regions of the surgical specimens, Twist expression was observed mainly in the ductal and myoepithelial cells of excretory ducts of salivary glands, with a cytoplasmic predominant pattern (Figure 1A). Focal reactivity was recorded in the acinar cells, most obvious in the intraoral minor salivary glands (Figure 1B). Also, Twist reactivity was noticed in the adnexal glands of the skin and in the oral and epidermal keratinocytes adjacent to invading neoplastic proliferations (Figure 1C). At the invasive tumor front, we also noticed Twist reactivity in the skeletal muscle fibers and adipocytes (Figure 1D).

From all investigated EMT inducing transcription factors, Twist was the most intensely expressed factor in tumor tissues, with an average IRS score of $6.875 \pm 1.979$, all investigated cases being positive. The reactivity was higher in the tumor specimens developed in the intraoral minor salivary glands (Figure 2A). Regardless the tumor topography, the solid variant was the most reactive to Twist, the reaction pattern being both nuclear and cytoplasmic, but most commonly nuclear (Figure 2B). The tumor reactivity decreased in the cribriform and tubular variants, and the cytoplasmic pattern was more prevalent (Figure 2, C and D). Also, the tumor reactivity was higher at the invasive front (Figure 2E) and in those cases that associated perineural invasion (Figure 2F) and lymph node metastases.

\section{Snail reactivity}

Regarding Snail reactivity, the remnants of normal salivary glandular parenchyma from surgical specimens showed reactivity especially at the level of parotid glands, more obvious in the acinar cells with both cytoplasmic and nuclear reactivity (Figure 3A). Instead, in the parenchyma of the other major salivary glands and at the level of the intraoral minor salivary glands, the Snail reactivity was more obvious in the cytoplasm of the ductal epithelial cells (Figure 3B). Reactivity was also noticed at the level of skeletal muscle fibers, smooth muscles, fibroblasts, lymphocytes, and in the oral squamous epithelial cells.

In the tumor samples, Snail reactivity was recorded in 20 cases $(62.5 \%$ of all investigated cases) and the average IRS score was about $2.9 \pm 2.716$. At the tumor parenchyma, the reactivity was heterogeneous with positive areas alternating with negative areas regardless of the HP variant or tumor topography. The nuclear pattern was more obvious in the solid variant and at the invasive front (Figure 3, C and D). The cytoplasmic pattern predominated especially in the cribriform and tubular variant (Figure 3, E and F). 
Regardless the HP variant or tumor topography, the tumor Snail reactivity seems to be higher in those cases that associated perineural invasion and lymph node metastases.

\section{Slug expression}

Slug transcription factor was positive in the normal salivary parenchyma, both in acinar and ductal epithelial cells but with variable intensity according to the topography of the salivary glands. In the major salivary glands, the highest intensity was in the cytoplasm of ductal epithelial cells (Figure 4A), while in the intraoral minor salivary glands, Slug reaction was more obvious in the cytoplasm of the acinar cells (Figure 4B). A weak Slug reactivity was also recorded in the basal and supra-basal keratinocytes of oral epithelium (Figure 4C) and epidermis (seen in those ACC with parotid development that invaded the superficial skin). At the same time, Slug reactivity was observed in the endothelial cells (Figure 4D), fibroblast and in the skeletal muscle fibers.

Regarding tumor Slug reactivity, positive reactions was recorded in $25 \mathrm{ACC}$ cases $\mathbf{7 8 . 1 2 \%}$ from all investigated cases). The average of IRS scores was about 5.28 \pm 3.215 without reactivity differences related to tumor topography. The prevalent cellular pattern was the cytoplasmic one, regardless HP ACC variants. The highest reactivity was noticed in the solid ACC variant, with the cytoplasmic pattern as most prevalent (Figure $5 \mathrm{~A}$ ). A lower reactivity was observed in the ACC cribriform and tubular variants (Figure 5, B and C). Also, a higher reactivity was noticed
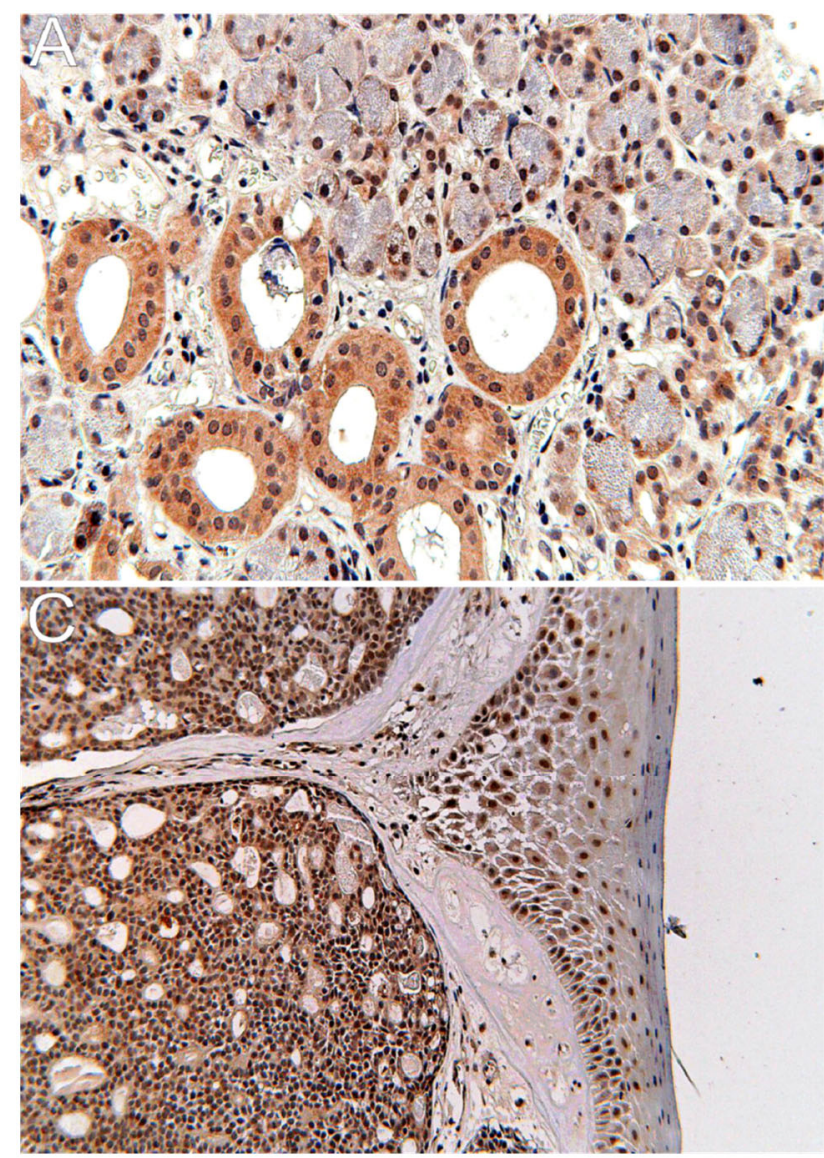

in the invasion front (Figure 5D) and in those cases that associated perineural invasion (Figure 5E) and lymph node metastases. Slug reactivity was also noticed in the stroma of ACCs at the level of fibroblasts and endothelial cells (Figure 5F).

\section{ZEB1 reactivity}

In the normal residual salivary gland parenchyma, we noticed a ZEB1 granular cytoplasmic reactivity, especially in the ductal epithelial cells (Figure 6A). Some reactivity was also noticed in the cytoplasm of keratinocytes from the lips' epithelium, in those cases of ACCs developed from lips minor salivary glands (Figure 6B). Moreover, ZEB1 reactivity was noticed in the endothelial cells, skeletal muscle fibers (Figure 6C), peripheral nerve fibers (Figure 6D), fibroblasts and adipocytes with nuclear pattern.

The tumor parenchyma was devoid of ZEB1 reactivity in all investigated ACC cases regardless tumor histopathology, tumor topography and pTNM stages. However, the tumor stroma was positive in all cases and this reactivity was obvious at the level of tumor associated fibroblasts and endothelial blood cells. Quantification of reactivity at this level revealed an average ZEB1 IRS score about $5.53 \pm 2.031$. We did not find any reactivity differences between different HP variants, but we noticed a higher reactivity at the invasion front (Figure $7, \mathrm{~A}-\mathrm{C}$ ) versus inside of the tumors (Figure 7, D-F). Moreover, a higher ZEB1 reactivity was also noticed in those ACC cases that associated perineural invasion and lymph node metastases.
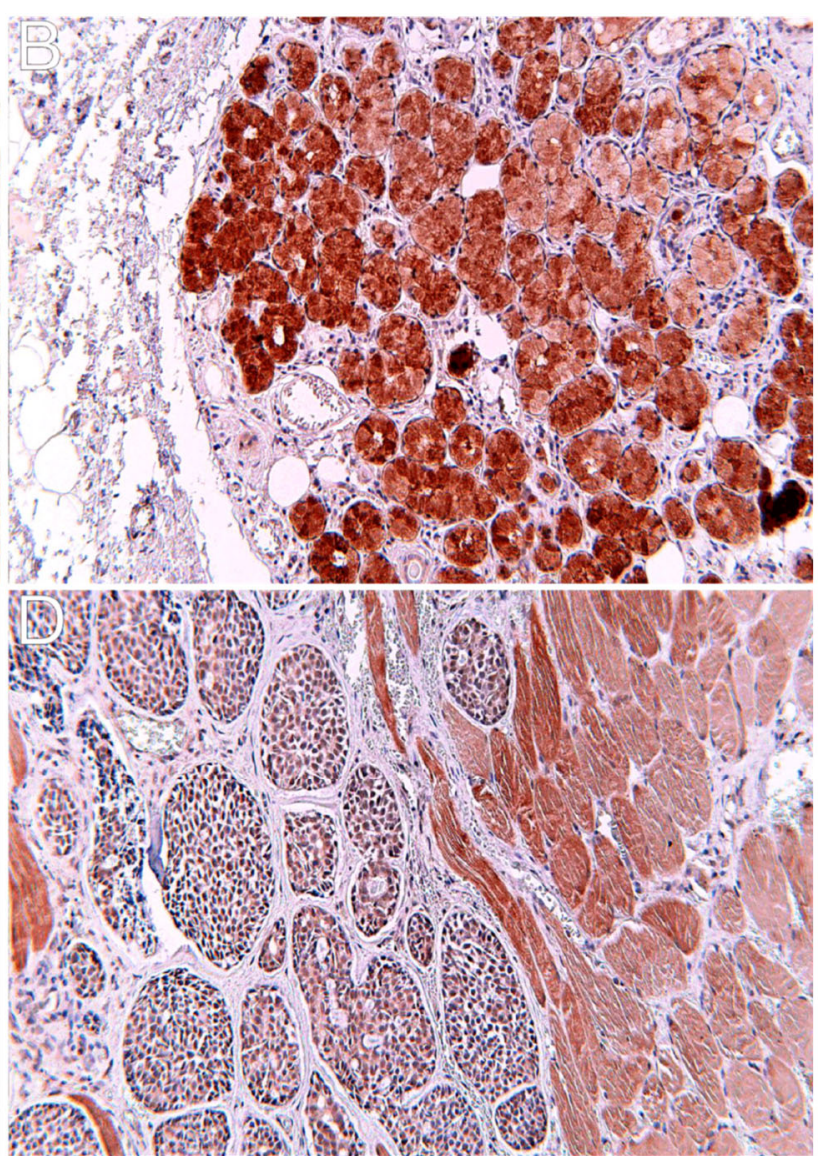

Figure 1 - Twist reactivity in the SACC surgical specimens: (A) Cytoplasmic intense reactivity in the ductal and myoepithelial cells of excretory ducts of salivary glands; (B) Focal cytoplasmic reactivity in the acinar cells, most obvious in the intraoral minor salivary glands; $(C)$ Nuclear reactivity in the oral and epidermal keratinocytes adjacent to invading neoplastic proliferations; (D) Cytoplasmic reactivity in the skeletal muscle fibers and adipocytes. Anti-Twist antibody immunolabeling: $(A) \times 400 ;(B-D) \times 200$. SACC: Salivary adenoid cystic carcinoma. 


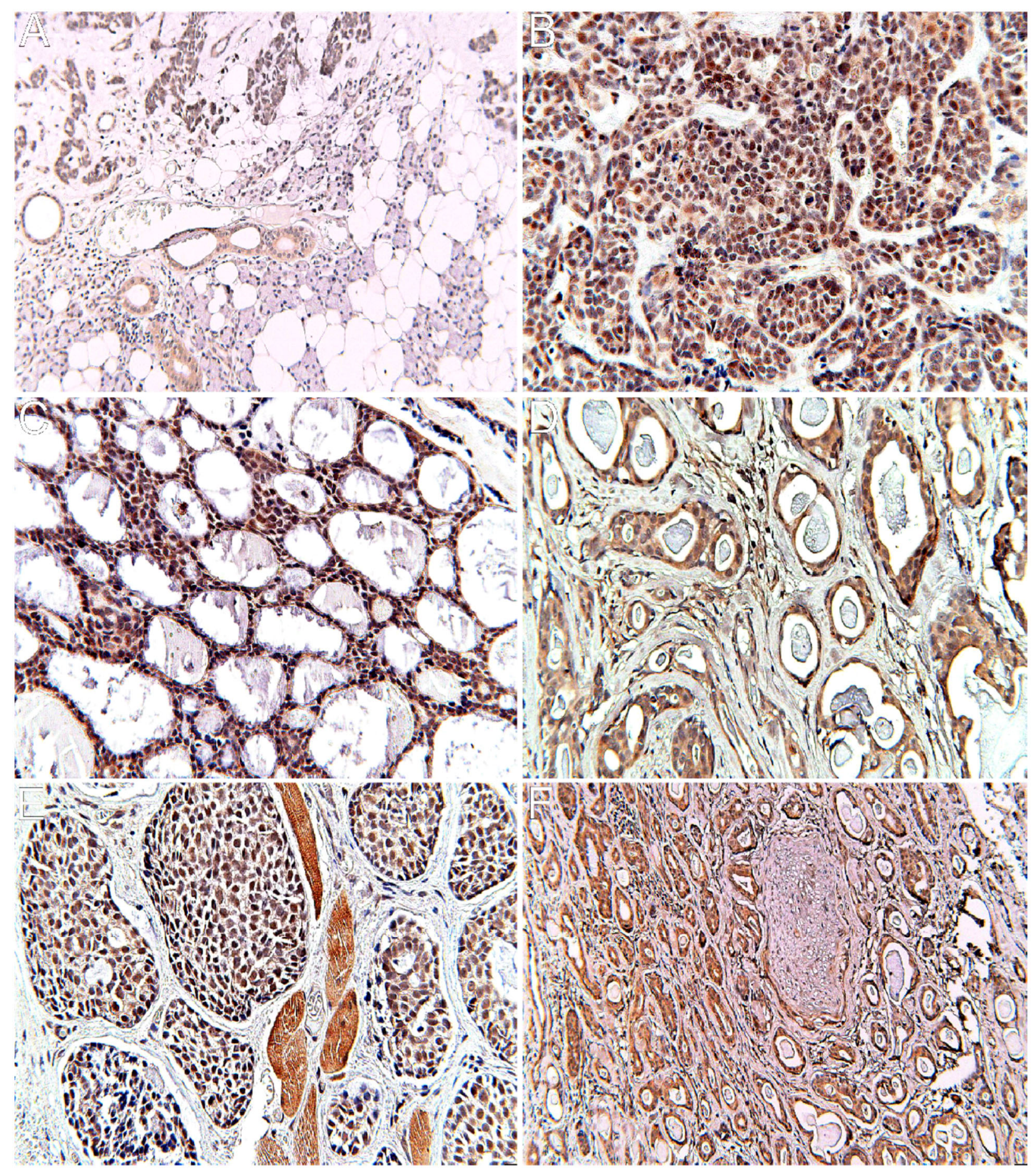

Figure 2 - Twist reactivity in the SACC surgical specimens: (A) Nuclear and cytoplasmic intense reactivity from tumors developed from sublingual minor salivary glands; $(B)$ Nuclear intense reactivity in the solid variant of a parotid tumor; (C) Nuclear and cytoplasmic reactivity in the cribriform variant of a parotid tumor; (D) Cytoplasmic predominant reactivity in the tubular variant of a parotid tumor; $(E)$ High and nuclear predominant reactivity at the invasive front of a submandibular salivary gland tumor; $(F)$ Both nuclear and cytoplasmic high reactivity in a sublingual salivary gland tumor with perineural invasion. Anti-Twist antibody immunolabeling: $(A$ and F) $\times 200 ;(B-E) \times 400$. SACC: Salivary adenoid cystic carcinoma. 

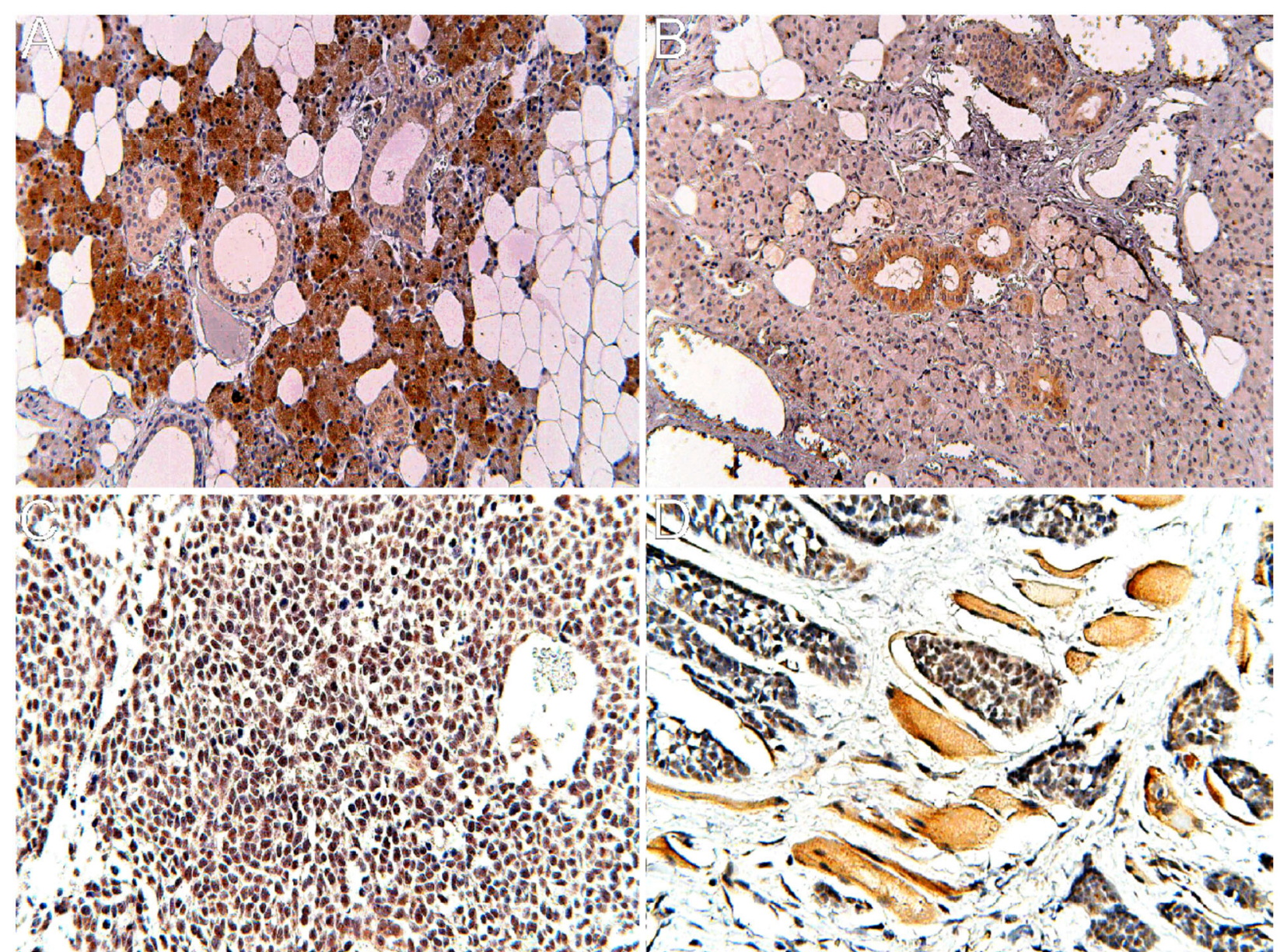

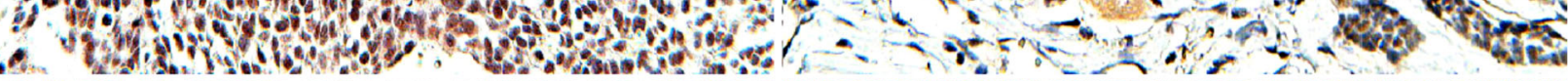

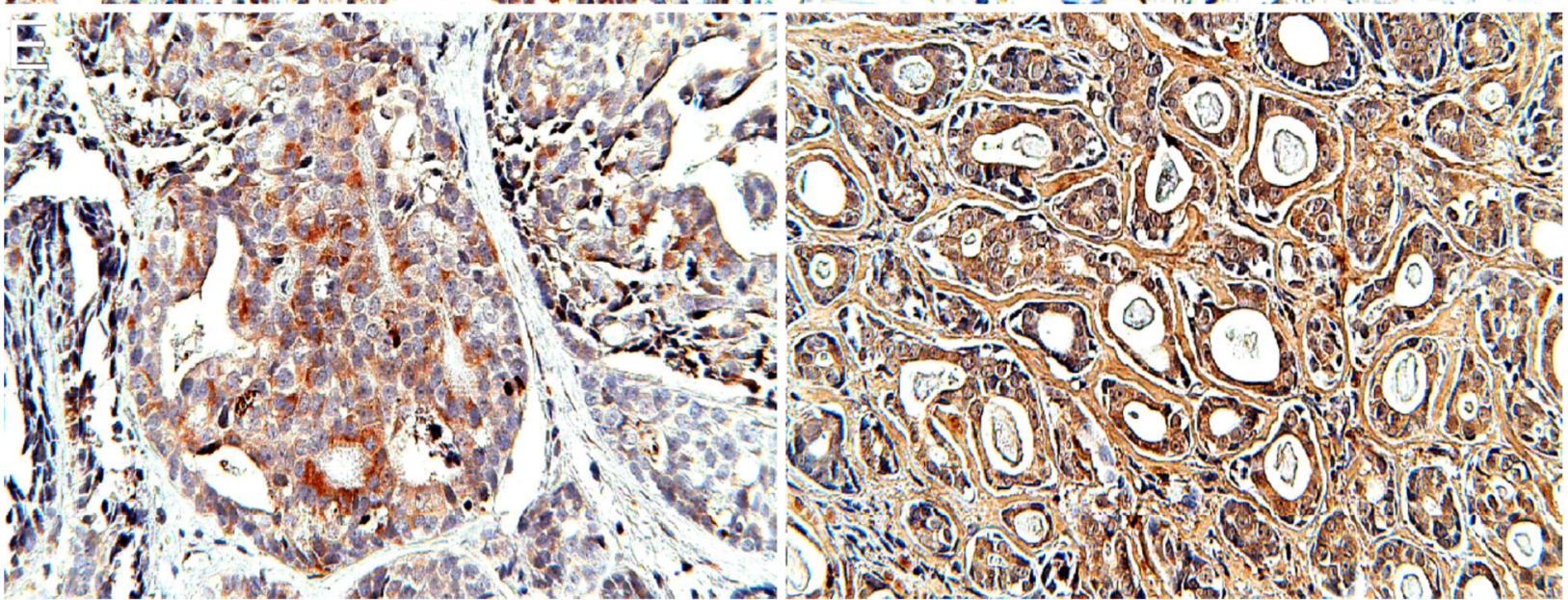

Figure 3 - Snail reactivity in the SACC surgical specimens: (A) Nuclear and cytoplasmic intense reactivity in the acinar cells of parotid glands; (B) Cytoplasmic reactivity of the ductal epithelial cells from intraoral minor salivary glands; (C) Nuclear reactivity in the solid variant of a parotid tumor; (D) Nuclear reactivity at invasion front in the solid variant of a parotid tumor; (E) Cytoplasmic predominant reactivity in cribriform variant of a parotid tumor; (F) Cytoplasmic predominant reactivity in tubular variant of a parotid tumor. Anti-Snail antibody immunolabeling: $(A$ and $B) \times 200$; $(C-F) \times 400$. SACC: Salivary adenoid cystic carcinoma. 


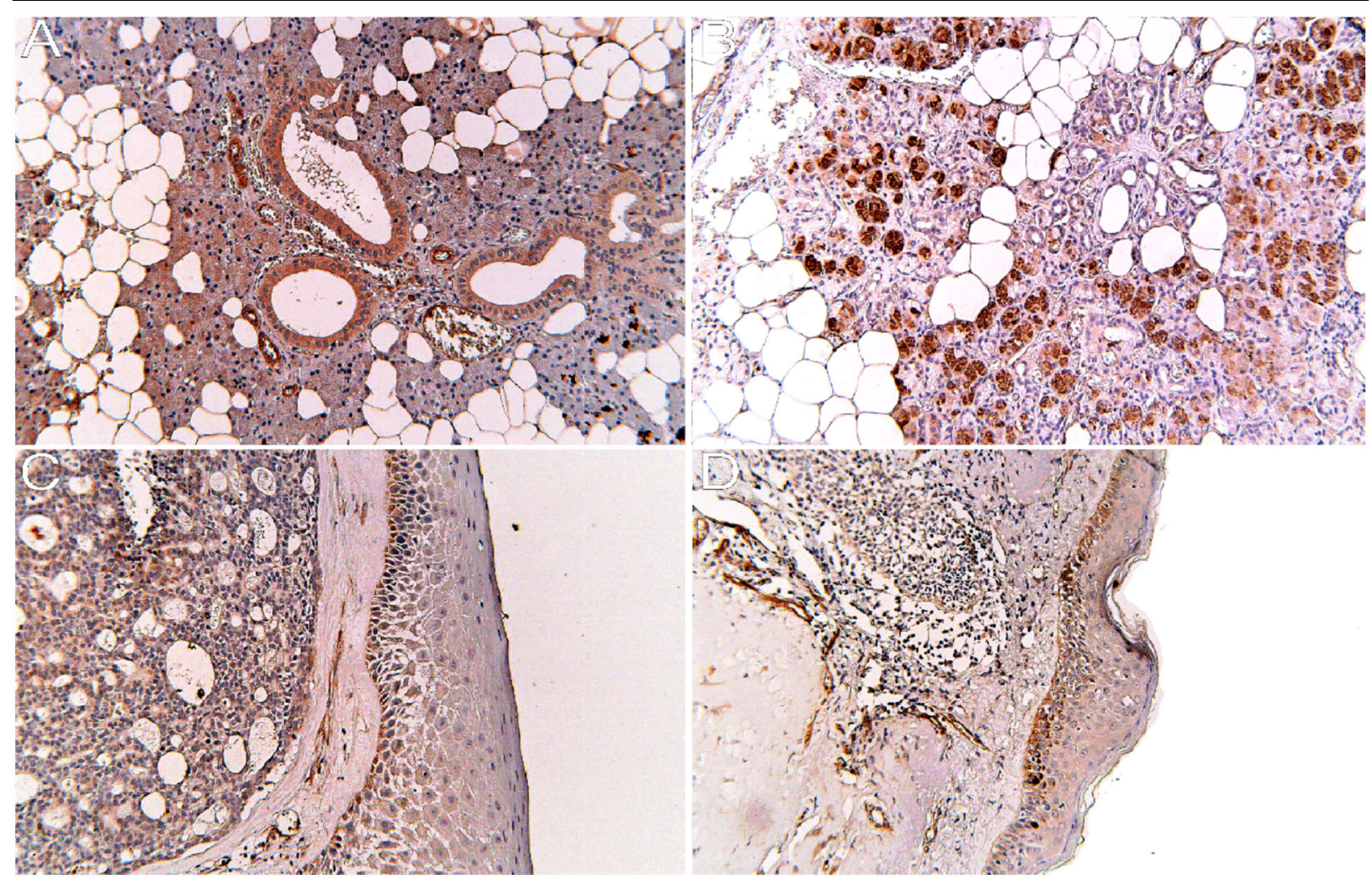

Figure 4 - Slug reactivity in the SACC surgical specimens: (A) Cytoplasmic reactivity in the ductal epithelial cells of parotid glands; (B) Cytoplasmic reactivity of acinar cells from intraoral minor salivary glands; (C) Weak cytoplasmic reactivity in the basal and supra-basal keratinocytes of oral epithelium; (D) Cytoplasmic reactivity in the endothelial cells. Anti-Slug antibody immunolabeling: $(A-D) \times 200$. SACC: Salivary adenoid cystic carcinoma.
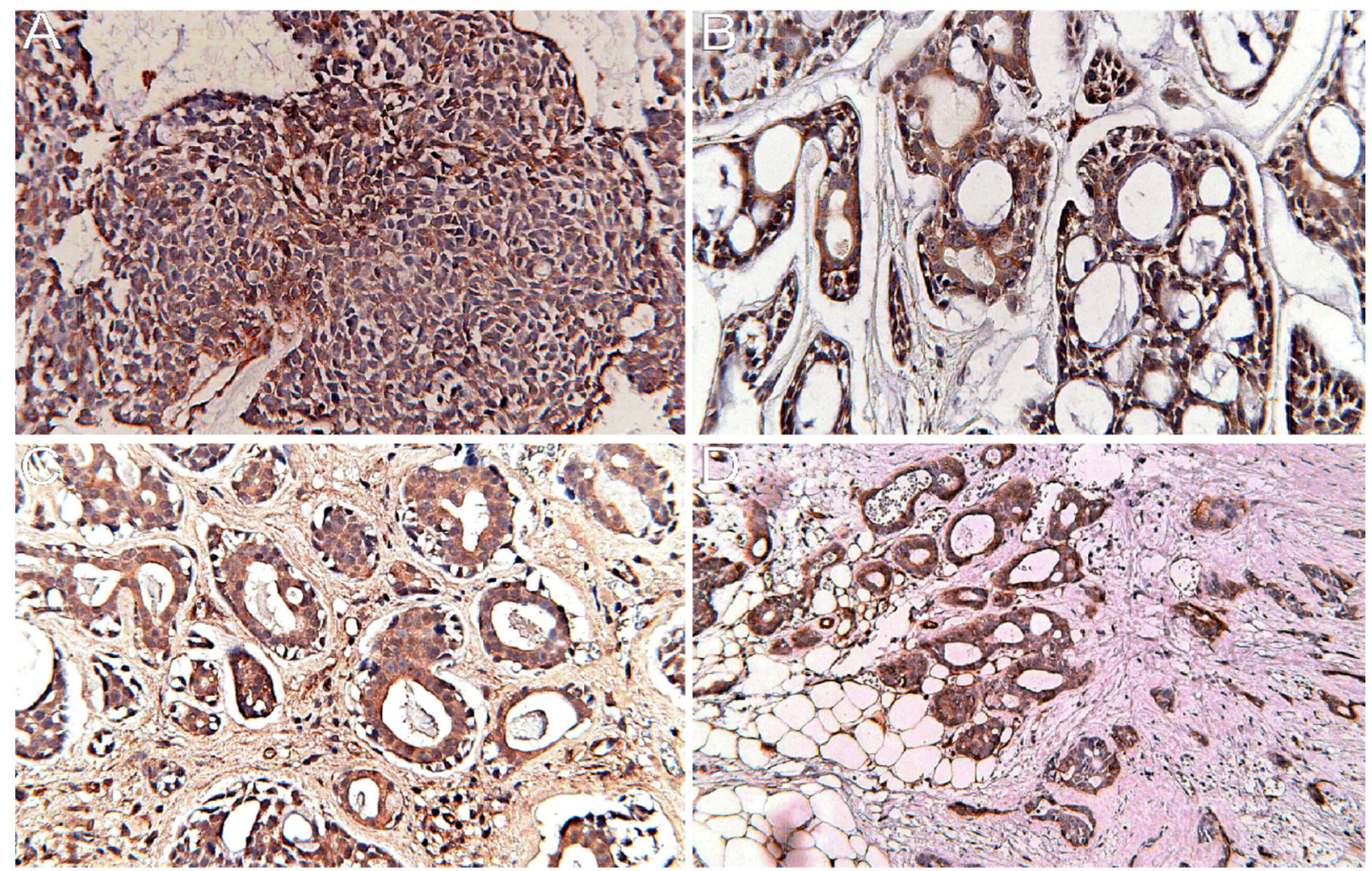

Figure 5 - Slug reactivity in the SACC surgical specimens: (A) Cytoplasmic intense reactivity in the solid ACC variant of parotid glands; (B) Cytoplasmic reactivity in cribriform variant of a parotid tumor; (C) Cytoplasmic reactivity in the tubular variant of a submandibular tumor; (D) Cytoplasmic intense reactivity at invasion front in the cribriform variant of a parotid tumor; (E) High cytoplasmic reactivity in a cribriform variant of a sublingual tumor with perineural invasion; (F) High cytoplasmic reactivity at the level of fibroblasts from a solid variant of a sublingual tumor. Anti-Slug antibody immunolabeling: $(A-C) \times 400 ;(D) \times 200$. SACC: Salivary adenoid cystic carcinoma. 


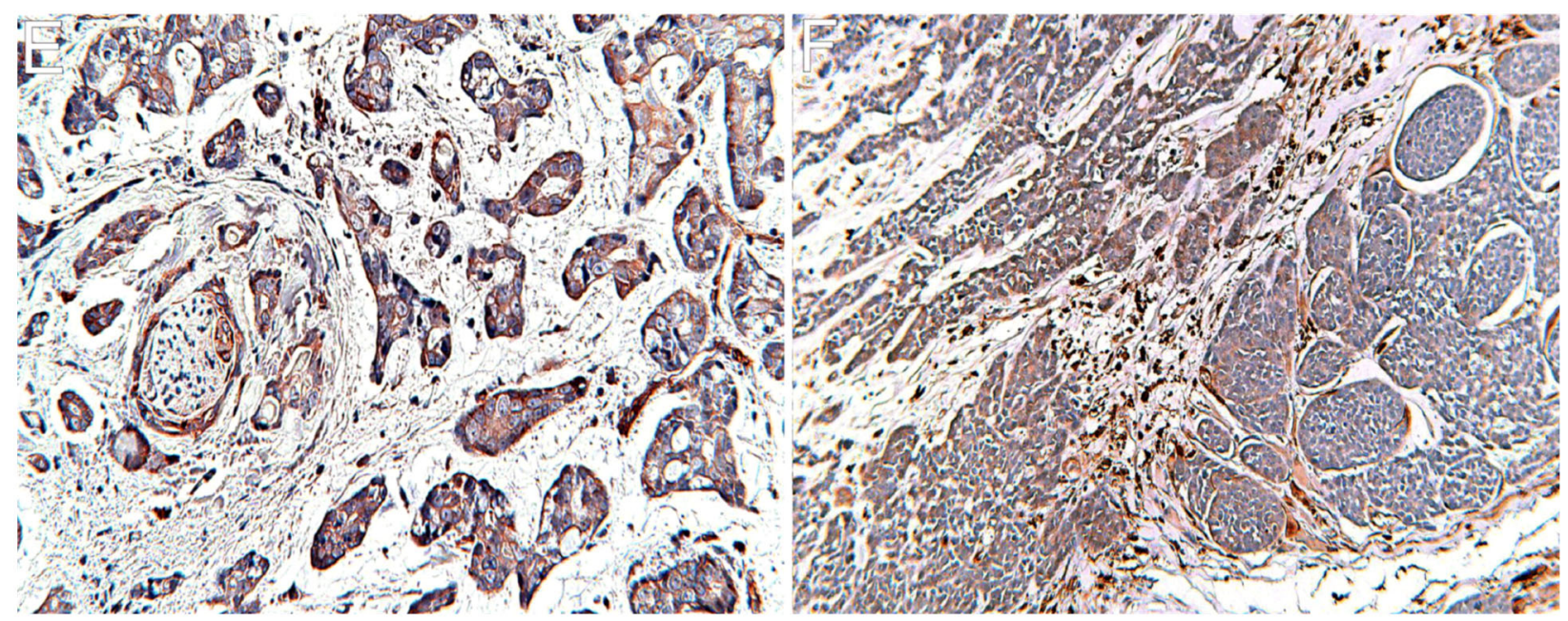

Figure 5 (continued) - Slug reactivity in the SACC surgical specimens: (E) High cytoplasmic reactivity in a cribriform variant of a sublingual tumor with perineural invasion; $(F)$ High cytoplasmic reactivity at the level of fibroblasts from a solid variant of a sublingual tumor. Anti-Slug antibody immunolabeling: $(E) \times 400 ;(F) \times 200$. SACC: Salivary adenoid cystic carcinoma.

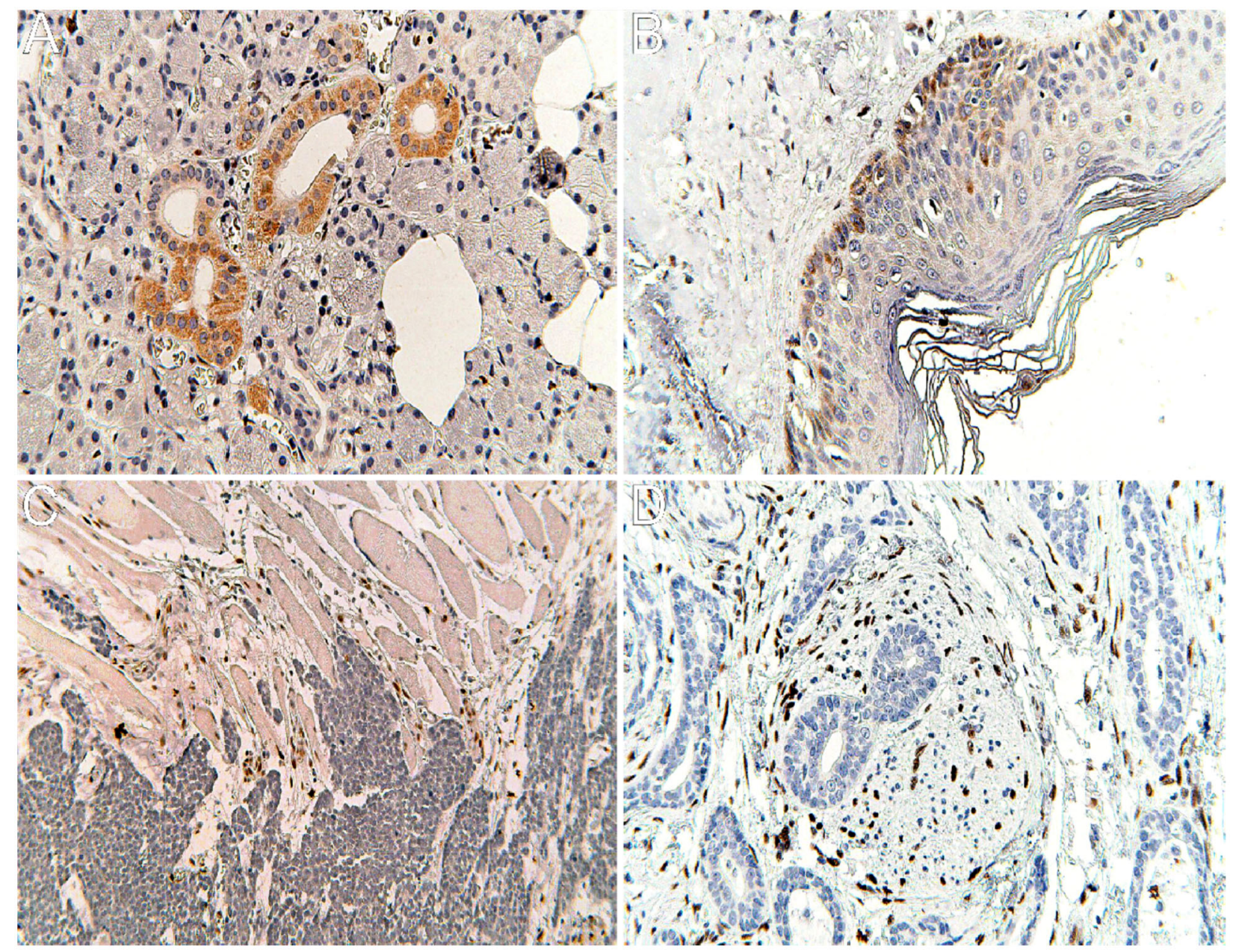

Figure 6-ZEB1 reactivity in the SACC surgical specimens: (A) Granular cytoplasmic reactivity in the ductal epithelial cells of lip salivary glands; (B) Cytoplasmic reactivity of keratinocytes from the lips epithelium in a lip SACC; (C) Weak cytoplasmic reactivity in the skeletal muscle fibers from the invasive front of a solid parotid tumor; (D) Reactivity in the peripheral nerve fibers in a lip SACC. Anti-ZEB1 antibody immunolabeling: $(A, C$ and D) $\times 200 ;(B) \times 400$. SACC: Salivary adenoid cystic carcinoma; ZEB1: Zinc finger E-box binding homeobox 1. 


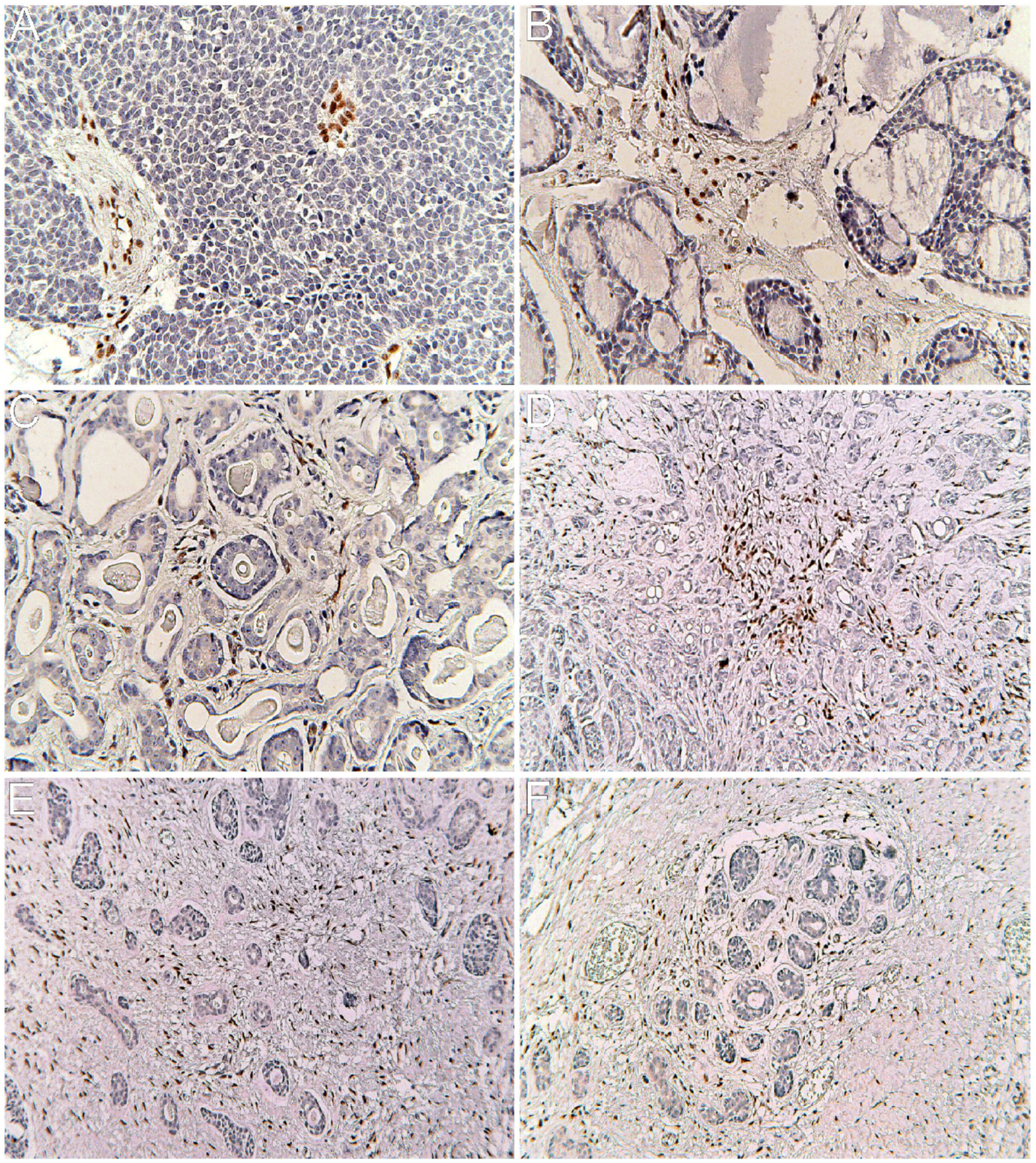

Figure 7 - ZEB1 reactivity in the SACC surgical specimens: (A) Negative reactivity in the tumor parenchyma of a solid ACC variant of parotid glands; (B) Negative reactivity in the tumor parenchyma of a cribriform variant of a submandibular tumor; (C) Negative reactivity in the tumor parenchyma of a tubular variant of a sublingual tumor; (D) Stromal reactivity at the invasive front in a solid variant of a parotid tumor; (E) Stromal reactivity at the invasive front in a cribriform variant of a submandibular tumor; $(F)$ Stromal reactivity at the invasive front in a tubular variant of a submandibular tumor. Anti-ZEB1 antibody immunolabeling: $(A-C) \times 400 ;(D-F) \times 200 . S A C C$ : Salivary adenoid cystic carcinoma; ZEB1: Zinc finger E-box binding homeobox 1.

\section{Statistical analysis}

The statistical investigation did not find a significant correlation between IHC scores and gender, tumor topography, HP variant, perineural invasion and pTNM stage. However, we found a direct moderate correlation between the IHC scores of all investigated biomarkers (Twist/Snail $-r=0.580, p<0.001$; Twist/Slug $-r=0.614$, $p<0.001$; Twist/ZEB1 $-r=0.619, p<0.001$; Snail/Slug $r=0.557, p<0.001$; Snail/ZEB1 $-r=0.676, p<0.001$; Slug/ZEB1 $-r=0.687, p<0.001$ ) (Figure $8, \mathrm{~A}-\mathrm{F}$ ). 

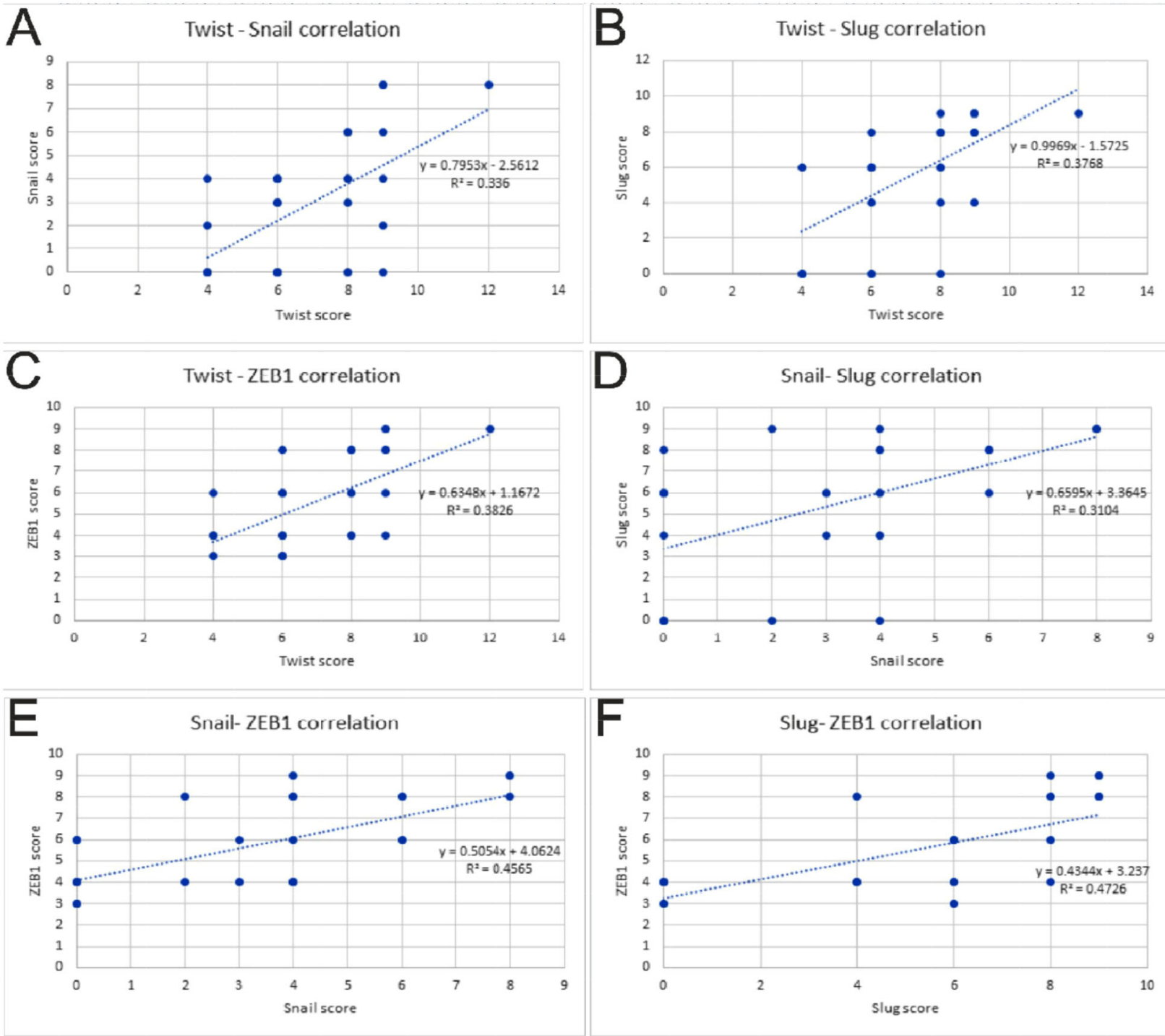

Figure 8 - Statistical analysis proving a direct moderate correlation between the IHC scores of all investigated biomarkers for our casuistry of SACC: (A) A moderate correlation between Twist and Snail IHC scores $(r=0.580, p<0.001)$; (B) A moderate correlation between Twist and Slug IHC scores $(r=0.614, p<0.001)$; $(C)$ A moderate correlation between Twist and ZEB1 IHC scores $(r=0.619, p<0.001)$; (D) A moderate correlation between Snail and Slug IHC scores $(r=0.557$, $p<0.001$ ); (E) A moderate correlation between Snail and ZEB1 IHC scores ( $r=0.676, p<0.001)$; $(F)$ A moderate correlation between Slug and ZEB1 IHC scores (r=0.687, p<0.001). SACC: Salivary adenoid cystic carcinoma; IHC: Immunohistochemical; ZEB1: Zinc finger E-box binding homeobox 1.

\section{ㅁ Discussions}

ACC is considered the most frequent malignancy of salivary glands with an annual global incidence of 1.5 cases per 100000 people [20]. The biological behavior of this salivary cancer is poorly understood, with a slow progression, but highly invasive and prone to nerve invasion and metastases. In the absence of effective molecular therapeutic targets, nowadays no curative treatments are available for patients with metastatic ACC [21]. Hence, the need for new in-depth studies on the molecular biology of these cancers, one of the new research directions aiming at the involving of the EMT process in the loco-regional aggressiveness of this type of cancer. The EMT process involves the disruption of intercellular adhesions, and cellular polarity, remodeling of the cytoskeleton, and changes in cell-matrix adhesion, things that allow enhancement of cell motility and their detachment from epithelial tumor cell blocks [22]. Thus, these cells acquire a mesenchymal-like phenotype, which is suitable for migration and, thus, for tumor invasion and metastasis. Earlier studies have shown that EMT seems to be a typical event in SACC metastasis [9, 10, 23]. EMT is a complex process with several interconnected transduction pathways, numerous factors being involved, such as transcription factors, epigenetic modifications, microribonucleic acids (miRNAs) and long non-coding RNAs [24]. The purpose of our study was to investigate the expression at the protein level of the most important transcription factors (Twist, Snail, Slug, and ZEB1) involved in the EMT process from the investigated ACC cases.

\section{Twist transcription factor}

Twist belong to the basic helix-loop-helix (bHLH) transcription factors family that have been implicated in cell lineage determination and differentiation, playing a 
key role in embryonic development [25]. After birth, their expression turns down and it remains restricted only to the precursor cells in adult tissues [26]. However, Twist overexpression has been found in many different carcinomas, including head and neck squamous cell carcinomas and its expression was associated with poor prognosis, high grade, invasive and metastatic lesions [26]. Several authors proved its involvement in tumor invasiveness, metastasis, growth, angiogenesis, and apoptosis inhibition, and even in the maintenance of cancer stem cells and the development of chemotherapy resistance [27-29]. The prometastatic Twist potential relies on its ability to induce an EMT process in cancer cells by turning-down the expression of epithelial specific markers, especially of the E-cadherin and by upregulating the expression of mesenchymal markers mainly of the N-cadherin [29-31].

In our study, the Twist expression in the normal tissues of the surgical specimens was restricted mainly to the ductal epithelial of salivary glands supporting the hypothesis of the ductal origin of SACC. In the tumor tissues, Twist was the most reactive transcriptional marker, all investigated cases being positive, and we recorded the highest IRS scores. We noticed differences in tumor Twist reactivity according to tumor topography and HP variants. Thus, we found that the highest Twist reactivity was noticed in ACC developed from intraoral minor salivary glands and in the solid histological variant. Also, we found that the Twist pattern reactivity had the tendency to shift the nuclear to cytoplasmic pattern from the solid ACC variant to the cribriform and tubular ACC variants. Moreover, Twist tumor reactivity seems to be higher at the invasive front and in those cases that associated perineural invasion and lymph node metastases.

Shen et al. (2010) showed that Twist expression was significantly higher in SACCs than in pleomorphic adenomas and normal parotid gland tissues suggesting that this marker could be associated with the development and progression of such salivary cancers [16]. Like us, the authors had also proved that Twist expression was significantly higher in the solid pattern of SACC compared to that of cribriform and tubular pattern and suspected its involvement in the regulation of cancer cell differentiation from this tumor. Moreover, the Twist expression level was higher in those cases that associated perineural invasion, compared to the group without perineural invasion, suggesting that this protein may be able to promote perineural invasion in such salivary cancers [16]. Also, the authors revealed the prognostic role of this marker by revealing that its expression was higher in cases with distant metastasis than that in those without distant metastasis, suggesting the involvement of this protein in the SACC metastasis by promoting the EMT process. Zhou et al. (2012) observed that overexpression of Twist induces EMT-like transformation of the metastatic cell lines of human SACC, with enhancing the migration and invasion abilities of these cells [32]. Pardis et al. (2016) recorded a high Twist expression in malignant salivary gland tumors, including ACC compared to normal glands and benign tumors, but they did not find any correlation with the size, stage or grade of tumor [33]. However, the authors proved the existence of a relationship between nuclear Twist expression and increasing tumor invasiveness in SACC, confirming the invasive behavior of these tumors.

\section{Snail transcription factor}

Snail was first reported in Drosophila melanogaster, where it has been shown to play a key role in mesoderm formation [34]. In vertebrates there were identify three members of this family of zinc-finger transcription factors, respectively: Snaill (Snail), Snail2 (Slug), and Snail3 (Smuc) [35]. In addition to the major role played in EMT induction, Snail is also involved in cell survival, immune regulation, and stem cell biology [36]. Its involvement in the EMT process is due mainly to the direct repression of E-cadherin transcription through direct binding to the E-cadherin promoter [37], but it also seems to be involved in promotion of $\mathrm{N}$-cadherin expression [38]. Moreover, it was proved for various human cancers that Snaill act as marker of aggressiveness, being considered a prognostic marker in these tumors [39-44].

In our study, at the level of the salivary gland parenchyma remnants, we noticed a cytoplasmic and nuclear Snail reactivity mostly in the parotid acinar cells, while for the other salivary glands the reactivity was mainly cytoplasmic and more obvious in the ductal epithelial cells. In tumor samples, Snail reactivity was recorded in $62.5 \%$ of investigated SACCs, and it was lower than Twist or Slug tumor reactivity. Overall, tumor reactivity was heterogeneous, positive areas alternating with negative zones regardless of the HP ACC variants or tumor topography. However, the nuclear pattern reactivity was more obvious in the solid variant and at the invasive front, while the cytoplasmic pattern predominated, especially in the cribriform and tubular variant. Also, we noticed the tendency for a higher reactivity in those cases associated with perineural invasion and lymph node metastases.

In the study conducted by Jiang et al. (2010), Snail reactivity with cytoplasmic and or nuclear pattern was observed in 58.68\% of the investigated SACCs [15]. Like in our work, these authors did not find any significant difference between Snail1 reactivity and tumor topography. The same authors recorded a higher Snaill reactivity in the solid variant of ACC, followed by the cribriform pattern and finally by the tubular variant [15]. Also, they found differences regarding Snaill reactivity and prognosis in different variants of SACCs, and elevated levels of this marker were significantly associated with perineural invasion, local regional recurrence, and distant metastasis. Zhao et al. (2013) proved that increased expression of Snail and Integrin-linked kinase (ILK) strongly correlated with the solid ACC variant, advanced TNM stages, high risk of recurrences and distant metastasis [45]. Also, the authors noticed that overexpression of Snail and N-cadherin and down regulation of E-cadherin correlated with a neural invasive phenotype of SACC. Liu et al. (2016) showed that epiregulin (EREG)-activated epidermal growth factor receptor (EGFR) stabilized Snail and Slug, which promoted EMT and metastatic features in SACC cells and targeting the EREG-EGFR-Snail/Slug axis could be an efficient treatment in metastatic SACCs [46]. In accordance with these data, Wang et al. (2018) found that that epidermal growth factor (EGF)-induced EGFR activation stabilized Snail expression and induced EMT in SACC and knockdown of Snail greatly suppressed EGF-induced EMT in these tumors [47]. 


\section{Slug transcription factor}

Slug member of the Snail family of zinc-finger transcription factors was first described in the neural crest and developing mesoderm in the chick embryos [48]. This protein is also found in most adult tissues that could help in the maintaining of their normal function after birth. Slug has activities similar to Snail, including E-cadherin transcriptional repression and anti-apoptotic activity and its expression is increased in many human cancers [40, $49,50]$. By its ability to alter E-cadherin and vimentin gene expression, this transcription marker is involved in tumor progression and invasiveness [11, 51-53].

Regarding Slug reactivity in the remaining salivary glandular parenchyma, our study showed a positive reaction both in ductal and acinar cells but with variable intensity according to the salivary gland topography. Thus, in major salivary gland, the highest reactivity was noticed in the cytoplasm of ductal epithelial cells, while for the intraoral minor salivary glands Slug reaction was more obvious in the cytoplasm of the acinar cells. In the tumor tissue, reactivity was recorded in $78.12 \%$ from all investigated cases, being the second most reactive studied EMT inducing transcription factors. Regardless the HP ACC variants, we noticed a prevalent cytoplasmic tumor reactivity with the highest scores in the solid ACC variant. Also, we observed a trend for a higher reactivity at the invasion front, and in those cases that associated perineural invasion and lymph node metastases. Moreover, tumor reactivity was also noticed in stroma, most obviously in fibroblast and endothelial cells.

Tang et al. (2010) reported that $71.9 \%$ from the investigated SACCs were reactive to Slug and excepting only four cases, the reactivity pattern was exclusively cytoplasmic [17]. Its tumor expression was significantly associated with tumor topography, TNM stages, HP variants, perineural invasion, local regional recurrence, and distant metastasis. The authors concluded that Slug is an independent and significant prognostic factor in SACCs, and it may be a useful therapeutic target in such salivary cancers [17]. He et al. (2013) proved that mitogen-activated protein kinase (MAPK)-Slug pathway has an important role in SACC metastasis [54]. Also, Wu et al. (2016) revealed that high expression of Slug and extracellular matrix metalloproteinase inducer (EMMPRIN) together with a low E-cadherin expression were significantly associated with perineural invasion and SACCs [55]. The authors, by a series of in vitro assays revealed Slug silencing could inhibit the EMT process by downregulating EMMPRIN and then upregulating E-cadherin in the perineural invasion of SACC. Also, Liu et al. (2016) proved that autocrine EREG-activated EGFR stabilize Snail and Slug and further induce EMT and metastatic features in SACC cells [46]. The authors concluded that EREG-EGFR-Snail/Slug axis is an important mechanism for SACC metastasis towards the lung and targeting the EGFR may provide an effective therapy for patients with SACC with autocrine EREG and no genetic EGFR mutation.

\section{ZEB1 transcription factor}

ZEB1 has a key role during normal embryonic development mainly by inducing EMT [56]. Also, by the same mechanism it seems to hold a critical role in invasion and metastasis of several types of human cancer [57]. By triggering EMT at the invasive front, it induces in the cancer cells a proinvasive and stem-like phenotype, being responsible of a worse clinical prognosis in most human malignancies [57, 58].

Investigating the ZEB1 reactivity in the residual salivary gland parenchyma, we observed a weak granular cytoplasmic reactivity, especially in the ductal epithelial cells. In the tumor parenchyma, we did not observe any positive reaction to ZEB1, regardless tumor histopathology, tumor topography and pTNM stages. However, the tumor stroma was positive in all cases and this reactivity was obvious at the level of tumor associated fibroblasts and endothelial blood cells. There were no significant differences between different HP variants, but we noticed a higher reactivity at the invasion front, and in those cases that associated perineural invasion and lymph node metastases. Statistically, we found a direct moderate correlation between the IHC scores of all investigated biomarkers, but no significant correlation between this immunoreactivity and the major clinical and morphological variable of the investigated SACCs.

Yao et al. (2017) proved that in oral squamous cell carcinomas, ZEB1 was overexpressed while the E-cadherin was downregulated and this immunoprofile was correlated with lymph node metastasis and pathological grading, and further on, these patients had a bad prognosis [59]. Moreover, in vitro and in vivo studies of tongue squamous cell carcinoma revealed that elevated levels of ZEB1 were accompanied by the downregulation of E-cadherin and upregulation of vimentin at the invasive front, conforming the role of this transcription factor in the promotion of EMT and invasion of these cancers [60]. Tang et al. (2014) showed that the endogenous messenger ribonucleic acid (mRNA) levels of Slug, Snail1, ZEB1, ZEB2, paired related homeobox protein 1 (Prrx1), homeobox B7 (HOXB7) were elevated in response to c-kit overexpression, contributing to SACC progression [61]. Also, Peng et al. (2017) proved in SACC that cancer cell-derived immunoglobulin G (cancer-IgG)-knockdown suppressed the EMT, as evidenced by the overexpression of E-cadherin and downregulation of Twist, Slug and ZEB1/2, as well as the reduced numbers of lamellipodia and disruption of F-actin filament arrangement [62]. The authors revealed a strong association between overexpression of cancer-IgG and metastasis, recurrence and invasion in such salivary cancers and they concluded that this marker could be useful to predict the prognosis of the disease. Moreover, Yao et al. (2018) showed that nuclear factor kappa B (NF- $\kappa$ B) could directly bind to the promoter region of ZEB1 and promote its transcription and insulin-like growth factor-binding protein 2 (IGFBP2), which is highly expressed in SACC plays an important role in invasion and metastasis in such cancers through the NF- $\kappa \mathrm{B} / \mathrm{ZEB} 1$ signaling pathway [18]. There are only a few studies available on ZEB1 expression on tumor endothelium, one of them highlighting that inactivation of endothelial ZEB1 impedes tumor progression and sensitizes tumors to conventional therapies, a fact that was also suspected by us [63]. In accordance with what we found, the latest literature data evidence indicates that ZEB1 protein is predominantly present in tumor stromal cells in various human cancer and it could play an important role in their progression $[64,65]$. 


\section{ㅁ Conclusions}

Our investigation revealed that most of SACCs were positive to the studied EMT inducing transcription factors, suggesting their implication in tumor differentiation, invasion, and metastasis of such salivary malignancies. Twist and Slug reactivity identified the solid variant of SACC as the most aggressive malignancy, especially for those cases developed from the intraoral minor salivary glands. Statistically, we found a direct moderate correlation between the IHC scores of all investigated biomarkers. These biomarkers could be used as prognostic factors and also as useful therapeutic targets for human SACC.

\section{Conflict of interests}

The authors declare that there is no conflict of interests regarding the publication of this paper. All authors read and approved the final manuscript.

\section{References}

[1] Boukheris H, Curtis RE, Land CE, Dores GM. Incidence of carcinoma of the major salivary glands according to the WHO classification, 1992 to 2006: a population-based study in the United States. Cancer Epidemiol Biomarkers Prev, 2009 , 18(11):2899-2906. https://doi.org/10.1158/1055-9965.EPI-090638 PMID: 19861510 PMCID: PMC2779732

[2] Hellquist $H$, Skalova A. Adenoid cystic carcinoma. In: Hellquist H, Skalova A (eds). Histopathology of the salivary glands. SpringerVerlag, Berlin-Heidelberg, 2014, 221-260. https://doi.org/10. 1007/978-3-540-46915-5 8

[3] Amit M, Binenbaum Y, Sharma K, Ramer N, Ramer I, Agbetoba A, Miles B, Yang X, Lei D, Bjøerndal K, Godballe C, Mücke T, Wolff KD, Fliss D, Eckardt AM, Copelli C, Sesenna E, Palmer F, Patel S, Gil Z. Analysis of failure in patients with adenoid cystic carcinoma of the head and neck. An international collaborative study. Head Neck, 2014, 36(7):998-1004. https:// doi.org/10.1002/hed.23405 PMID: 23784851

[4] Chang CF, Hsieh MY, Chen MK, Chou MC. Adenoid cystic carcinoma of head and neck: a retrospective clinical analysis of a single institution. Auris Nasus Larynx, 2018, 45(4):831837. https://doi.org/10.1016/j.anl.2017.10.009 PMID: 29653784

[5] Gamboa-Hoil SI, Silva-Godínez JC, Abrego-Vásquez JA Adenoid cystic carcinoma of head and neck. A 5-year retrospective study: experience in a single third-level reference center. Cir Cir, 2020, 88(1):34-40. https://doi.org/10.24875/ CIRU.19000919 PMID: 31967612

[6] Lupinetti AD, Roberts DB, Williams MD, Kupferman ME, Rosenthal DI, Demonte F, El-Naggar A, Weber RS, Hanna EY. Sinonasal adenoid cystic carcinoma: the M. D. Anderson Cancer Center experience. Cancer, 2007, 110(12):2726-2731. https://doi.org/10.1002/cncr.23096 PMID: 17960615

[7] Shingaki S, Kanemaru S, Oda Y, Niimi K, Mikami T, Funayama A, Saito C. Distant metastasis and survival of adenoid cystic carcinoma after definitive treatment. J Oral Maxillofac Surg Med Pathol, 2014, 26(3):312-316. https://doi.org/10.1016/j. ajoms.2013.09.013

[8] Li N, Xu L, Zhao H, El-Naggar AK, Sturgis EM. A comparison of the demographics, clinical features, and survival of patients with adenoid cystic carcinoma of major and minor salivary glands versus less common sites within the Surveillance, Epidemiology, and End Results registry. Cancer, 2012, 118(16): 3945-3953. https://doi.org/10.1002/cncr.26740 PMID: 22179977 PMCID: PMC3412946

[9] Dong L, Ge XY, Wang YX, Yang LQ, Li SL, Yu GY, Gao Y, Fu J. Transforming growth factor- $\beta$ and epithelial-mesenchymal transition are associated with pulmonary metastasis in adenoid cystic carcinoma. Oral Oncol, 2013, 49(11):1051-1058. https:// doi.org/10.1016/j.oraloncology.2013.07.012 PMID: 23962790

[10] Yang X, Jing D, Liu L, Shen Z, Ju J, Ma C, Sun M. Downregulation of $p 53$ promotes in vitro perineural invasive activity of human salivary adenoid cystic carcinoma cells through epithelial-mesenchymal transition-like changes. Oncol Rep, 2015, 33(4):1650-1656. https://doi.org/10.3892/or.2015.3750 PMID: 25625376
[11] Bolós V, Peinado H, Pérez-Moreno MA, Fraga MF, Esteller M, Cano A. The transcription factor Slug represses E-cadherin expression and induces epithelial to mesenchymal transitions: a comparison with Snail and E47 repressors. J Cell Sci, 2003, 116(Pt 3):499-511. https://doi.org/10.1242/jcs.00224 PMID: 12508111

[12] Kang Y, Massagué J. Epithelial-mesenchymal transitions: Twist in development and metastasis. Cell, 2004, 118(3):277-279. https://doi.org/10.1016/j.cell.2004.07.011 PMID: 15294153

[13] Yang J, Mani SA, Donaher JL, Ramaswamy S, Itzykson RA, Come C, Savagner P, Gitelman I, Richardson A, Weinberg RA. Twist, a master regulator of morphogenesis, plays an essential role in tumor metastasis. Cell, 2004, 117(7):927-939. https:// doi.org/10.1016/j.cell.2004.06.006 PMID: 15210113

[14] Vandewalle C, Comijn J, De Craene B, Vermassen P, Bruyneel E, Andersen H, Tulchinsky E, Van Roy F, Berx G. SIP1/ZEB2 induces EMT by repressing genes of different epithelial cell-cell junctions. Nucleic Acids Res, 2005, 33(20): 6566-6578. https://doi.org/10.1093/nar/gki965 PMID: 16314317 PMCID: PMC1298926

[15] Jiang J, Tang Y, Zhu G, Zheng M, Yang J, Liang X. Correlation between transcription factor Snail1 expression and prognosis in adenoid cystic carcinoma of salivary gland. Oral Surg Oral Med Oral Pathol Oral Radiol Endod, 2010, 110(6):764-769. https://doi.org/10.1016/j.tripleo.2010.06.015 PMID: 20952218

[16] Shen M, Wen Y, Hua C, Xiao J. The expression of Twist in salivary adenoid cystic carcinoma and its clinicopathological significance. Chin Ger J Clin Oncol, 2010, 9(4):187-192. https://doi:10.1007/s10330-010-0028-4

[17] Tang Y, Liang X, Zhu G, Zheng M, Yang J, Chen Y. Expression and importance of zinc-finger transcription factor Slug in adenoid cystic carcinoma of salivary gland. J Oral Pathol Med, 2010, 39(10):775-780. https://doi.org/10.1111/j.1600-0714. 2010.00913.x PMID: 20738754

[18] Yao X, Wang Y, Duan Y, Zhang Q, Li P, Jin R, Tao Y, Zhang W, Wang $X$, Jing C, Zhou X. IGFBP2 promotes salivary adenoid cystic carcinoma metastasis by activating the NF- $K B / Z E B 1$ signaling pathway. Cancer Lett, 2018, 432:38-46. https://doi. org/10.1016/j.canlet.2018.06.008 PMID: 29885520

[19] Remmele W, Stegner HE. Vorschlag zur einheitlichen Definition eines Immunreaktiven Score (IRS) für den immunhistochemischen Östrogenrezeptor-Nachweis (ER-ICA) im Mammakarzinomgewebe [Recommendation for uniform definition of an immunoreactive score (IRS) for immunohistochemical estrogen receptor detection (ER-ICA) in breast cancer tissue]. Pathologe, 1987, 8(3):138-140. PMID: 3303008

[20] Ellington CL, Goodman M, Kono SA, Grist W, Wadsworth T, Chen AY, Owonikoko T, Ramalingam S, Shin DM, Khuri FR, Beitler JJ, Saba NF. Adenoid cystic carcinoma of the head and neck: incidence and survival trends based on 1973-2007 Surveillance, Epidemiology, and End Results data. Cancer, 2012, 118(18):4444-4451. https://doi.org/10.1002/cncr.27408 PMID: 22294420

[21] Yarbrough WG, Panaccione A, Chang MT, Ivanov SV. Clinical and molecular insights into adenoid cystic carcinoma: neural crest-like stemness as a target. Laryngoscope Investig Otolaryngol, 2016, 1(4):60-77. https://doi.org/10.1002/lio2.22 PMID: 28894804 PMCID: PMC5510248

[22] Roche J. The epithelial-to-mesenchymal transition in cancer. Cancers (Basel), 2018, 10(2):52. https://doi.org/10.3390/cancers 10020052 PMID: 29462906 PMCID: PMC5836084

[23] Dong L, Wang YX, Li SL, Yu GY, Gan YH, Li D, Wang CY. TGF-beta1 promotes migration and invasion of salivary adenoid cystic carcinoma. J Dent Res, 2011, 90(6):804-809. https:// doi.org/10.1177/0022034511401407 PMID: 21441221

[24] Georgakopoulos-Soares I, Chartoumpekis DV, Kyriazopoulou V, Zaravinos A. EMT factors and metabolic pathways in cancer. Front Oncol, 2020, 10:499. https://doi.org/10.3389/fonc.2020. 00499 PMID: 32318352 PMCID: PMC7154126

[25] Isenmann S, Arthur A, Zannettino ACW, Turner JL, Shi S, Glackin CA, Gronthos S. TWIST family of basic helix-loophelix transcription factors mediate human mesenchymal stem cell growth and commitment. Stem Cells, 2009, 27(10):24572468. https://doi.org/10.1002/stem.181 PMID: 19609939

[26] Puisieux A, Valsesia-Wittmann S, Ansieau S. A twist for survival and cancer progression. $\mathrm{Br} \mathrm{J}$ Cancer, 2006, 94(1):13-17. https://doi.org/10.1038/sj.bjc.6602876 PMID: 16306876 PMCID: PMC2361066 
[27] Khan MA, Chen HC, Zhang D, Fu J. Twist: a molecular target in cancer therapeutics. Tumour Biol, 2013, 34(5):2497-2506 https://doi.org/10.1007/s13277-013-1002-x PMID: 23873099

[28] Roberts CM, Tran MA, Pitruzzello MC, Wen W, Loeza J, Dellinger TH, Mor G, Glackin CA. TWIST1 drives cisplatin resistance and cell survival in an ovarian cancer model, via upregulation of GAS6, L1CAM, and Akt signalling. Sci Rep, 2016, 6:37652. https://doi.org/10.1038/srep37652 PMID: 27876874 PMCID: PMC5120297

[29] Seyedmajidi M, Seifi S, Moslemi D, Mozaffari SF, Gholinia H, Zolfaghari Z. Immunohistochemical expression of TWIST in oral squamous cell carcinoma and its correlation with clinicopathologic factors. J Cancer Res Ther, 2018, 14(5):964-969. https://doi.org/10.4103/0973-1482.224350 PMID: 30197332

[30] Li R, Wu C, Liang H, Zhao Y, Lin C, Zhang X, Ye C. Knockdown of TWIST enhances the cytotoxicity of chemotherapeutic drugs in doxorubicin-resistant HepG2 cells by suppressing MDR1 and EMT. Int J Oncol, 2018, 53(4):1763-1773. https:// doi.org/10.3892/ijo.2018.4495 PMID: 30066890

[31] Weiss MB, Abel EV, Mayberry MM, Basile KJ, Berger AC Aplin AE. TWIST1 is an ERK1/2 effector that promotes invasion and regulates MMP-1 expression in human melanoma cells. Cancer Res, 2012, 72(24):6382-6392. https://doi.org/10.1158/ 0008-5472.CAN-12-1033 PMID: 23222305 PMCID: PMC 3531871

[32] Zhou C, Liu J, Tang Y, Zhu G, Zheng M, Jiang J, Yang J, Liang $X$. Coexpression of hypoxia-inducible factor-2 $\alpha$, TWIST2, and SIP1 may correlate with invasion and metastasis of salivary adenoid cystic carcinoma. J Oral Pathol Med, 2012, 41(5):424-431. https://doi.org/10.1111/j.1600-0714.2011.01 114.x PMID: 22103974

[33] Pardis S, Zare R, Jaafari-Ashkavandi Z, Ashraf MJ, Khademi B. Twist expression in pleomorphic adenoma, adenoid cystic carcinoma and mucoepidermoid carcinoma of salivary glands. Turk Patoloji Derg, 2016, 32(1):15-21. https://doi.org/10.51 46/tjpath.2015.01343 PMID: 26832177

[34] Alberga A, Boulay JL, Kempe E, Dennefeld C, Haenlin M. The Snail gene required for mesoderm formation in Drosophila is expressed dynamically in derivatives of all three germ layers. Development, 1991, 111(4):983-992. PMID: 1879366

[35] Nieto MA. The Snail superfamily of zinc-finger transcription factors. Nat Rev Mol Cell Biol, 2002, 3(3):155-166. https:// doi.org/10.1038/nrm757 PMID: 11994736

[36] Wu Y, Zhou BP. Snail: more than EMT. Cell Adh Migr, 2010 4(2):199-203. https://doi.org/10.4161/cam.4.2.10943 PMID: 20168078 PMCID: PMC2900613

[37] Peinado H, Portillo F, Cano A. Transcriptional regulation of cadherins during development and carcinogenesis. Int J Dev Biol, 2004, 48(5-6):365-375. https://doi.org/10.1387/ijdb.04 1794hp PMID: 15349812

[38] Gil D, Ciołczyk-Wierzbicka D, Dulińska-Litewka J, Zwawa K McCubrey JA, Laidler P. The mechanism of contribution of integrin linked kinase (ILK) to epithelial-mesenchymal transition (EMT). Adv Enzyme Regul, 2011, 51(1):195-207. https://doi.org/ 10.1016/j.advenzreg.2010.09.005 PMID: 21035499

[39] Blanco MJ, Moreno-Bueno G, Sarrio D, Locascio A, Cano A, Palacios J, Nieto MA. Correlation of Snail expression with histological grade and lymph node status in breast carcinomas. Oncogene, 2002, 21(20):3241-3246. https://doi.org/10.1038/ sj.onc.1205416 PMID: 12082640

[40] Elloul S, Elstrand MB, Nesland JM, Tropé CG, Kvalheim G Goldberg I, Reich R, Davidson B. Snail, Slug, and Smadinteracting protein 1 as novel parameters of disease aggressiveness in metastatic ovarian and breast carcinoma. Cancer, 2005, 103(8):1631-1643. https://doi.org/10.1002/cncr.20946 PMID: 15742334

[41] Hardy RG, Vicente-Dueñas C, González-Herrero I, Anderson C Flores T, Hughes S, Tselepis C, Ross JA, Sánchez-García I. Snail family transcription factors are implicated in thyroid carcinogenesis. Am J Pathol, 2007, 171(3):1037-1046. https:// doi.org/10.2353/ajpath.2007.061211 PMID: 17724139 PMCID: PMC1959496

[42] Miyoshi A, Kitajima Y, Kido S, Shimonishi T, Matsuyama S, Kitahara K, Miyazaki K. Snail accelerates cancer invasion by upregulating MMP expression and is associated with poor prognosis of hepatocellular carcinoma. $\mathrm{Br} \mathrm{J}$ Cancer, 2005, 92(2):252-258. https://doi.org/10.1038/sj.bjc.6602266 PMID: 15668718 PMCID: PMC2361838
[43] Olmeda D, Montes A, Moreno-Bueno G, Flores JM, Portillo F, Cano A. Snai1 and Snai2 collaborate on tumor growth and metastasis properties of mouse skin carcinoma cell lines. Oncogene, 2008, 27(34):4690-4701. https://doi.org/10.1038/ onc.2008.118 PMID: 18408755

[44] Yang MH, Chang SY, Chiou SH, Liu CJ, Chi CW, Chen PM, Teng SC, Wu KJ. Overexpression of NBS1 induces epithelialmesenchymal transition and co-expression of NBS1 and Snail predicts metastasis of head and neck cancer. Oncogene, 2007, 26(10):1459-1467. https://doi.org/10.1038/sj.onc.120 9929 PMID: 16936774

[45] Zhao D, Yang K, Tang XF, Lin NN, Liu JY. Expression of integrin-linked kinase in adenoid cystic carcinoma of salivary glands correlates with epithelial-mesenchymal transition markers and tumor progression. Med Oncol, 2013, 30(3):619. https:// doi.org/10.1007/s12032-013-0619-3 PMID: 23729269

[46] Liu S, Ye D, Xu D, Liao Y, Zhang L, Liu L, Yu W, Wang Y, He Y, Hu J, Guo W, Wang T, Sun B, Song H, Yin H, Liu J, Wu Y, Zhu H, Zhou BP, Deng J, Zhang Z. Autocrine epiregulin activates EGFR pathway for lung metastasis via EMT in salivary adenoid cystic carcinoma. Oncotarget, 2016, 7(18):25251-25263. https:// doi.org/10.18632/oncotarget.7940 PMID: 26958807 PMCID: PMC5041901

[47] Wang Y, Hu J, Wang Y, Ye W, Zhang X, Ju H, Xu D, Liu L, Ye D, Zhang L, Zhu D, Deng J, Zhang Z, Liu S. EGFR activation induced Snail-dependent EMT and myc-dependent PD-L1 in human salivary adenoid cystic carcinoma cells. Cell Cycle, 2018, 17(12):1457-1470. https://doi.org/10.1080/15384101. 2018.1489177 PMID: 29954240 PMCID: PMC6132955

[48] Nieto MA, Sargent MG, Wilkinson DG, Cooke J. Control of cell behavior during vertebrate development by Slug, a zinc finger gene. Science, 1994, 264(5160):835-839. https://doi.org/10. 1126/science.7513443 PMID: 7513443

[49] Ganesan R, Mallets E, Gomez-Cambronero J. The transcription factors Slug (SNAI2) and Snail (SNAI1) regulate phospholipase D (PLD) promoter in opposite ways towards cancer cell invasion. Mol Oncol, 2016, 10(5):663-676. https://doi.org/ 10.1016/j.molonc.2015.12.006 PMID: 26781944 PMCID: PMC4870114

[50] Storci G, Sansone P, Trere D, Tavolari S, Taffurelli M, Ceccarelli C, Guarnieri T, Paterini P, Pariali M, Montanaro L, Santini D, Chieco P, Bonafé M. The basal-like breast carcinoma phenotype is regulated by SLUG gene expression. J Pathol, 2008, 214(1):25-37. https://doi.org/10.1002/path.2254 PMID: 17973239

[51] Alves CC, Carneiro F, Hoefler H, Becker KF. Role of the epithelial-mesenchymal transition regulator Slug in primary human cancers. Front Biosci (Landmark Ed), 2009, 14:30353050. https://doi.org/10.2741/3433 PMID: 19273255

[52] Côme C, Arnoux V, Bibeau F, Savagner P. Roles of the transcription factors Snail and Slug during mammary morphogenesis and breast carcinoma progression. J Mammary Gland Biol Neoplasia, 2004, 9(2):183-193. https://doi.org/10.1023/ B:JOMG.0000037161.91969.de PMID: 15300012 PMCID: PMC2259229

[53] Shih JY, Tsai MF, Chang TH, Chang YL, Yuan A, Yu CJ, Lin SB Liou GY, Lee ML, Chen JJ, Hong TM, Yang SC, Su JL, Lee YC, Yang PC. Transcription repressor Slug promotes carcinoma invasion and predicts outcome of patients with lung adenocarcinoma. Clin Cancer Res, 2005, 11(22):8070-8078. https:// doi.org/10.1158/1078-0432.CCR-05-0687 PMID: 16299238

[54] He Q, Zhou X, Li S, Jin Y, Chen Z, Chen D, Cai Y, Liu Z, Zhao T, Wang A. MicroRNA-181a suppresses salivary adenoid cystic carcinoma metastasis by targeting MAPK-Snai2 pathway. Biochim Biophys Acta, 2013, 1830(11):5258-5266. https:// doi.org/10.1016/j.bbagen.2013.07.028 PMID: 23911747

[55] Wu B, Wei J, Hu Z, Shan C, Wang L, Zhang C, Yang X, Yang X, Lei $D$. Slug silencing inhibited perineural invasion through regulation of EMMPRIN expression in human salivary adenoid cystic carcinoma. Tumour Biol, 2016, 37(2):2161-2169. https:// doi.org/10.1007/s13277-015-4043-5 PMID: 26349748

[56] Vandewalle C, Van Roy F, Berx G. The role of the ZEB family of transcription factors in development and disease. Cell Mol Life Sci, 2009, 66(5):773-787. https://doi.org/10.1007/s000 18-008-8465-8 PMID: 19011757

[57] Zhang P, Sun Y, Ma L. ZEB1: at the crossroads of epithelialmesenchymal transition, metastasis and therapy resistance. 
Cell Cycle, 2015, 14(4):481-487. https://doi.org/10.1080/153 84101.2015.1006048 PMID: 25607528 PMCID: PMC4614883

[58] Yun EJ, Baek ST, Xie D, Tseng SF, Dobin T, Hernandez E, Zhou J, Zhang L, Yang J, Sun H, Xiao G, He D, Kittler R, Hsieh JT. DAB2IP regulates cancer stem cell phenotypes through modulating stem cell factor receptor and ZEB1. Oncogene, 2015, 34(21):2741-2752. https://doi.org/10.1038/ onc.2014.215 PMID: 25043300

[59] Yao X, Sun S, Zhou X, Zhang Q, Guo W, Zhang L. Clinicopathological significance of ZEB-1 and E-cadherin proteins in patients with oral cavity squamous cell carcinoma. Onco Targets Ther, 2017, 10:781-790. https://doi.org/10.2147/OTT. S111920 PMID: 28243114 PMCID: PMC5315354

[60] Kurihara K, Isobe T, Yamamoto G, Tanaka Y, Katakura A, Tachikawa T. Expression of BMI1 and ZEB1 in epithelialmesenchymal transition of tongue squamous cell carcinoma. Oncol Rep, 2015, 34(2):771-778. https://doi.org/10.3892/or. 2015.4032 PMID: 26043676

[61] Tang YL, Fan YL, Jiang J, Li KD, Zheng M, Chen W, Ma XR, Geng N, Chen QM, Chen Y, Liang XH. C-kit induces epithelialmesenchymal transition and contributes to salivary adenoid cystic cancer progression. Oncotarget, 2014, 5(6):1491-1501. https://doi.org/10.18632/oncotarget.1606 PMID: 24721839 PMCID: PMC4039226
[62] Peng J, Wang HC, Liu Y, Jiang JH, Lv WQ, Yang Y, Li CY, Qiu XY. Involvement of non-B cell-derived immunoglobulin $G$ in the metastasis and prognosis of salivary adenoid cystic carcinoma. Oncol Lett, 2017, 14(4):4491-4498. https://doi.org/ 10.3892/ol.2017.6782 PMID: 29085446 PMCID: PMC5649563

[63] Fu R, Li Y, Jiang N, Ren BX, Zang CZ, Liu LJ, Lv WC, Li HM, Weiss S, Li ZY, Lu T, Wu ZQ. Inactivation of endothelial ZEB1 impedes tumor progression and sensitizes tumors to conventional therapies. J Clin Invest, 2020, 130(3):12521270. https://doi.org/10.1172/JCI131507 PMID: 32039918 PMCID: PMC7269596

[64] Bronsert P, Kohler I, Timme S, Kiefer S, Werner M, Schilling O, Vashist Y, Makowiec F, Brabletz T, Hopt UT, Bausch D, Kulemann B, Keck T, Wellner UF. Prognostic significance of zinc finger E-box binding homeobox 1 (ZEB1) expression in cancer cells and cancer-associated fibroblasts in pancreatic head cancer. Surgery, 2014, 156(1):97-108. https://doi.org/ 10.1016/j.surg.2014.02.018 PMID: 24929761

[65] Fu R, Han CF, Ni T, Di L, Liu LJ, Lv WC, Bi YR, Jiang N, He Y, Li HM, Wang S, Xie H, Chen BA, Wang XS, Weiss SJ, Lu T, Guo QL, Wu ZQ. A ZEB1/p53 signaling axis in stromal fibroblasts promotes mammary epithelial tumours. Nat Commun, 2019, 10(1):3210. https://doi.org/10.1038/s41467-019-11278-7 PMID: 31324807 PMCID: PMC6642263

\section{Corresponding authors}

Claudiu Mărgăritescu, Professor, MD, PhD, Department of Pathology, Faculty of Dentistry, University of Medicine and Pharmacy of Craiova, 2 Petru Rareş Street, 200349 Craiova, Romania; Phone +40740-152 550, e-mail: c_margaritescu2000@yahoo.com

Maria Cristina Munteanu, Lecturer, MD, PhD, Department of Oral and Maxillofacial Surgery, Faculty of Dentistry, University of Medicine and Pharmacy of Craiova, 2 Petru Rareş Street, 200349 Craiova, Romania; Phone +40730335 575, e-mail: cristina_omf@yahoo.com 